\title{
The Identity Crisis of Osteoarthritis
}

Ann Fam Med 2015;13(6):iii. doi:10.1370/afm.1878.

The Annals of Family Medicine encourages readers to develop a learning community of those seeking to improve health care and health through enhanced primary care. You can participate by conducting a RADICAL journal club and sharing the results of your discussions in the Annals online discussion for the featured articles. RADICAL is an acronym for Read, Ask, Discuss, Inquire, Collaborate, Act, and Learn. The word radical also indicates the need to engage diverse participants in thinking critically about important issues affecting primary care and then acting on those discussions. ${ }^{1}$

\section{HOW IT WORKS}

In each issue, the Annals selects an article or articles and provides discussion tips and questions. We encourage you to take a RADICAL approach to these materials and to post a summary of your conversation in our online discussion. (Open the article online and click on "TRACK discussion: Submit a comment.") You can find discussion questions and more information online at: http://www.AnnFamMed.org/site/AJC/.

\section{CURRENT SELECTION}

\section{Article for Discussion}

Paskins Z, Sanders T, Croft P, Hassell A. The identity crisis of osteoarthritis in general practice: a qualitative study using video-stimulated recall. Ann Fam Med. 2015;13(6):537-544.

\section{Discussion Tips}

Rarely do we get a chance to reflect on both the patient and the clinician perspective on the care we provide. This study uses videotapes of visits between patients and their general practice physicians to stimulate interpretations from both parties, and then carefully draws the cross-cutting lessons.

\section{DISCUSSION QUESTIONS}

- What question is asked by this study and why does it matter?

- How does this study advance beyond previous research and clinical practice on this topic?

- How strong is the study design for answering the question?

- To what degree can the findings be accounted for by:

1. How participants were selected?

2. Saturation (additional sampling doesn't yield substantial new information)?

3. How the data were analyzed?

4. How the findings were interpreted?

- What are the main study findings? What general and osteoarthritis-specific communication issues are identified?

- How comparable is the study sample to similar patients in your practice? What is your judgment about the transportability of the findings?

-What contextual factors are important for interpreting the findings?

- How might this study change your practice? Policy? Education? Research?

- Who the constituencies are for the findings, and how they might be engaged in interpreting or using the findings?

-What are the next steps in interpreting or applying the findings?

- What researchable questions remain?

\section{References}

1. Stange KC, Miller WL, McLellan LA, et al. Annals Journal Club: It's time to get RADICAL. Ann Fam Med. 2006;4(3):196-197. http:// annfammed.org/content/4/3/196. 